\title{
Association between overweight and academic achievement among affluent school children in Allahabad
}

Author for Correspondence :

\section{NEHA BANSAL}

Department of Home Science, University of Allahabad, ALLAHABAD (U.P.) INDIA Email : nehamanish.bansal@gmail. com
ABSTRACT : Psychological and social health problems related to overweight may affect academic achievement of overweight children. The purpose of the present study was to assess the relationship between overweight and academic achievement in school children. A total of 330 , school children studying between $6^{\text {th }}$ and $10^{\text {th }}$ standard aged between 11 to 16 years were studied from two affluent schools of Allahabad city- Maharshi Patanjali Vidya Mandir and Tagore Public School. Children with BMI between $85^{\text {th }}$ and $95^{\text {th }}$ percentile were considered as overweight. 165 identified overweight children as cases and 165 normal weight children as controls were selected. While selecting controls, it was kept in mind to maintain the similarity of age, gender and standard between case and control. Cumulative Grade Point Average (CGPA) along with Math and English grades were recorded from the school register to evaluate the academic achievement of children. Chi square test was used for statistical analysis. Findings of the study reveal that there is no significant difference $(p>0.05)$ between cases and controls with respect to grades achieved in CGPA, Math and English in both boys and girls. Overall, overweight was not found significantly associated to children's academic achievement. More research studies are required to further explore the relationship between excess body weight and academic achievement

KEY WORDS: Overweight, Academic achievement, School children

- HOW TO CITE THIS PAPER : Bansal, Neha (2016). Association between overweight and academic achievement among affluent school children in Allahabad. Asian J. Home Sci., 11 (1) : 62-65, DOI: 10.15740/ HAS/AJHS/11.1/62-65. 